\title{
O CONTEXTO DE UM SERVIÇO DE EMERGÊNCIA: com a palavra, o usuário*
}

Maria Luiza Machado Ludwig**

Ana Lúcia de Lourenzi Bonilha***

\section{Resumo}

O presente artigo é parte de uma pesquisa qualitativa do tipo estudo de caso, tendo a observação livre, a pesquisa documental e a entrevista não estruturada como recursos para a obtenção de informações. O trabalho teve como objetivo conhecer a compreensão do usuário de um serviço de emergência, sobre o contexto onde ele é atendido, no que se refere ao ambiente e à forma como ocorre este atendimento. O grupo de participantes foi composto por doze indivíduos adultos, internados no hospital, após terem sido atendidos na unidade de emergência. Como resultado da análise dos dados, obteve-se as seguintes categorias: qualquer coisa, passa na emergência; aquela seleção; aqui se faz tudo; não é nada agradável; só tenho a agradecer.

Descritores: serviço hospitalar de emergência; SUS (BR); prestação de cuidados de saúde

\section{Abstract}

This article presents parts of a qualitative research of a "case-study" type. Through free observation, documents research and a nonstructured interview the information was gathered. The purpose of this work was to become aware of the user's understanding of an emergency service, considering the environment and the way he/she was treated. The group of participants for this matter were in 12 adults in which became inpatients after being examined at the emergency service. After analysing the data, the result was obtained and divided in the following categories: anything you need, go to the emergency service that assessment; here everything is done; it isn't pleasant at all; I only have to thank.

Descriptors: emergency service hospital; SUS $(B R)$; delivery of health care

Title: The context of an emergency service: with the word, the user

\section{Resumen}

El presente artículo hace parte de una pesquisa cualitativa del tipo estudio de caso, teniendo la observación libre, la pesquisa documental y la entrevista no estructurada como recursos para la obtención de la informaciones. El objectivo de este trabajo es conocer la comprensión del usuario de un servicio de emergencia, sobre el contexto de donde esta siendo atendido, con referencia al ambiente y la forma como ocurre este atendimiento. El grupo de participantes era compuesto por dose individuos adultos, internados en el hospital, despues de atendidos en la unidad de emergencia. Como resultado de la análisis de los datos, obtubimos las seguientes categorias: cualquier cosa, pasar en la emergencia aquella selección; aquí se hace de todo; no es nada agradable; solo tengo que agradecer.

Descriptores: servicio de urgencia en hospital; SUS (BR); prestación de atención de salud

Título: El contexto de un servicio de emergencia: con la palabra, el usuario

\section{Contextualização da temática}

Os serviços de emergência hospitalares constituíramse, na última década, em locais onde a população, usualmente, procura por soluções para suas necessidades de saúde.

Estes serviços são procurados por propiciarem "[...] meios para uma pronta avaliação médica do doente e facilidades que implementam uma ação terapêutica, com o trabalho de equipes especificamente treinadas" (1:3). Além disso, pode ser pontuado também como fator determinante de procura, a disponibilidade do serviço, que funciona 24 horas por dia. Desta forma, a população tem acesso a um nível de resolutividade mais alto para seu problema imediato, pois a procura resultará no mínimo, em uma avaliação de saúde, com realização de exames diagnósticos, ainda que represente uma solução paliativa para sua necessidade.

Deste modo, pode-se perceber que a procura dos serviços de emergência ocorre em detrimento de outros serviços e está, intimamente, relacionada às distorções do sistema de saúde vigente e suas implicações.

Com as mudanças ocorridas no sistema de saúde nas últimas décadas, hoje, diferentemente do que acontecia no passado, a totalidade da população brasileira tem a garantia legal ao cuidado de saúde gratuito, independentemente de possuir um vínculo empregatício. Para chegar a esta realidade, o nosso sistema de saúde, em sua evolução histórica, passou por várias alterações, culminando, no final da década de 80 , com a criação do Sistema Único de Saúde - SUS.

O SUS foi implantado como forma de fazer com que o artigo 196 da Constituição Brasileira de 1988 seja garantido. Este diz que:

a saúde é um direito de todos e dever do Estado, garantido mediante políticas sociais e econômicas que visem à redução do risco de doenças e de outros agravos e ao acesso universal e igualitário as ações e serviços para sua promoção, proteção e recuperação(2:133)

De uma maneira simplificada, pode-se dizer que o SUS propõe um modelo onde todos os cidadãos, independentemente de sua posição sócio-econômica, possuem o direito a acessar os serviços de saúde e receber cuidados que satisfaçam suas necessidades de forma integral, em uma rede hierarquizada de acordo com a complexidade do atendimento.

O excesso de demanda por atendimento que vem ocorrendo nos serviços de emergência, denuncia a ineficiência do sistema de saúde em operacionalizar a sua proposta, uma vez que esta procura retratar a dificuldade do usuário em acessar outros serviços de saúde, como por exemplo, os de atenção primária. Embora isso ocorra, observa-se quotidianamente que os serviços de emergência tentam cumprir seu papel perante a sociedade para atender a demanda. Porém, mesmo com o esforço do conjunto de profissionais e com adaptações na estrutura física, o resultado tem se traduzido em superlotação, e inevitavelmente tem culminado em uma queda

* Artigo elaborado a partir de dissertação de mestrado apresentada em 2000 ao Curso de Mestrado em Enfermagem da Escola de Enfermagem da Universidade Federal do Rio Grande do Sul.

** Enfermeira. Mestre em Enfermagem. Professora Assistente do Departamento de Enfermagem Médico-Cirúrgica da Escola de Enfermagem da UFRGS.

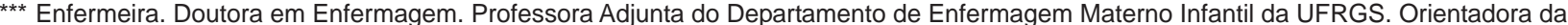
dissertação.

E-mail do autor: bonilha@enf.ufrgs.br 
significativa na qualidade do atendimento prestado.

O fenômeno da superlotação que ocorre nas emergências por um lado é resultado desta indisponibilidade de serviços, e por outro, gerado pela escassez de leitos na rede hospitalar integrada ao SUS. Desta forma, acaba-se criando outro fenômeno, denominado de "universalização excludente", causando uma inversão da porta de entrada no sistema de saúde, descaracterizando o princípio da hierarquização dos níveis de atendimento ${ }^{(3)}$.

Pode-se constatar que o usuário não vê no SUS um sistema hierarquizado, e este se configura em um dos motivos que o leva a procurar pelo serviço que the ofereça maior resolutividade e, em contrapartida, o sistema de saúde, desarticulado, não consegue trabalhar a demanda, com vistas a torná-la uma demanda organizada, e assim colocar em prática a hierarquização da assistência. Há que se considerar também que o usuário busca este tipo de serviço de acordo com a sua prioridade, que muitas vezes não coincide com as da instituição, uma vez que estão envolvidos neste processo de percepção da doença e necessidade de buscar auxílio, fatores culturais inerentes à inserção social dos usuários.

Com base nestas reflexões, a presente pesquisa teve como elemento desencadeador minha permanência como docente em um serviço de emergência de um hospital-escola integrado ao SUS. Este contexto me fez observar as dificuldades encontradas pelo usuário no serviço, ao sofrer as conseqüências de receber atendimento em um ambiente superlotado.

Deste modo, algumas questões foram delineadas para dar suporte ao estudo:

a) como o usuário compreende o atendimento no serviço de emergência?

b) o fato de se encontrar em um ambiente superlotado o incomoda?

c) ou será que a garantia do atendimento supera o desconforto?

Assim, o objetivo deste estudo foi buscar a compreensão do usuário do serviço de emergência sobre o contexto em que ocorreu o seu atendimento, durante a sua passagem pelo serviço, no que se refere ao ambiente e à forma como se deu este atendimento.

\section{Metodologia}

Neste estudo, partiu-se da convicção de que a experiência humana somente pode ser definida por quem a vive e que o contexto influencia de modo decisivo, resultando na construção de um juízo em relação ao fenômeno experienciado. Com base nestas considerações, optou-se pela metodologia qualitativa com a realização de um estudo de caso $^{(4)}$.

Os participantes da investigação foram usuários adultos do Serviço de Emergência do Hospital de Clínicas de Porto Alegre. O grupo foi composto de doze indivíduos, internados no hospital, após terem sido atendidos na unidade de emergência. Foi utilizado como critério de seleção, que os mesmos apresentassem condições, tanto física quanto mentais, de manter um diálogo.

Para esta investigação, como estratégias metodológicas, além das informações verbais e consultas a documentos do Serviço, foram utilizadas as técnicas de observação livre ${ }^{(5)}$ e entrevista não estruturada ${ }^{(4)}$. A observação do contexto, característica de um estudo de caso, ocorreu no local onde acontece o atendimento ao usuário do Serviço, privilegiando sua chegada, bem como a trajetória percorrida no setor.

Buscando delimitar o número de participantes necessários para esta fase da investigação, foi utilizado como critério a reincidência de informações ${ }^{(6)}$. Desta forma, foram realizadas doze entrevistas, gravadas em fita-cassete, com autorização do participante e posteriormente transcritas e digitadas.

O procedimento para análise das informações obtidas seguiu a proposta de interpretação qualitativa de dados $^{(4)}$, ou seja, a construção de um conjunto de categorias descritivas com o aprofundamento teórico das mesmas com base no objetivo do estudo, nas observações, pesquisa documental e entrevistas.

A pesquisa foi submetida a avaliação pelo Comitê de Ética do Hospital de Clínicas de Porto Alegre, atendendo à Resolução 196 do Conselho Nacional de Saúde, tendo sido aprovada para seu desenvolvimento.

Os participantes foram solicitados a assinar o Termo de Consentimento Livre e Esclarecido, ficando com uma cópia do documento em seu poder.

\subsection{Com a palavra, o usuário}

A seguir, são apresentadas as cinco categorias obtidas no processo de categorização de dados ${ }^{(4)}$, as quais recebem uma denominação inspirada nos depoimentos dos usuários, por retratarem a maneira como os mesmos compreendem o contexto de atendimento no Serviço de Emergência em estudo.

\subsection{Qualquer coisa, passa na emergência}

A procura por um serviço de saúde pode ser determinada por diversos fatores. Estes podem ser de ordem pessoal e estar relacionados à capacidade financeira de custear a própria saúde e a dos familiares, bem como ligados à noção que o indivíduo possui de saúde e doença.

Assim, é importante considerar, nesta análise, que o indivíduo antes de eleger o serviço para se tratar, passa por um processo de percepção de sua situação de saúde. Tal processo é resultante do aparecimento dos sintomas, os quais dizem respeito ao caráter invisível da doença, sendo exclusivos ao doente e manifestam-se por sensações que só podem ser descritas por meio das palavras de quem as experimenta ${ }^{(7)}$. Deste modo, indivíduos provenientes de culturas e contextos distintos poderão interpretar o mesmo sintoma de maneiras completamente diferentes ${ }^{(8)}$.

O indivíduo, ao perceber sua situação de saúde como merecedora de atenção, elege um serviço para satisfazer esta necessidade de saúde. Ao realizar esta procura, estará utilizando seu próprio conhecimento como forma de diagnóstico, caracterizando um modelo assistencial em que a procura se dá somente quando o indivíduo se sente doente. "Este modelo, portanto, tende a atender os indivíduos que na dependência do seu grau de conhecimento e/ou sofrimento, procuram por 'livre iniciativa' os serviços de saúde" (9:458).

É neste modelo assistencial que se encontram situados os serviços de emergência, uma vez que grande parte de seus usuários são atendidos a partir da procura espontânea, provocada pelos fatores já explicitados. No Serviço em estudo, uma pesquisa demonstrou que $50 \%$ dos indivíduos que lá consultam são originários de demanda espontânea ${ }^{(10)}$.

Por outro lado, além da percepção de sentir-se doente, o indivíduo poderá optar pelo tipo de atendimento, com base na noção de gravidade. A procura pela assistência se dá com base na classificação das doenças em "simples" e "grave" e os serviços de saúde são também classificados segundo estas categorias. Assim, coisas simples podem ser resolvidas no "postinho", ficando com o "hospital" a função de tratar as 
situações percebidas como graves ${ }^{(11)}$.

É com base nesta percepção de gravidade que a Emergência pode ser procurada, enquanto integrante da instituição hospitalar, como relata um usuário deste estudo ao ser questionado sobre o motivo que o levou até lá:

era polmão, me deu pontada né, no polmão, primeira vez deu do lado direito, e agora me deu dupla a apontada, e comecei a escarrá sangue, comecei a ficá ruim [...] (João, 44 anos)

Por outro lado, a procura ao Serviço de Emergência pode ser motivada por referências pessoais, que se traduzem tanto por referências obtidas de outras pessoas, quanto pela experiência de já ter se tratado no local. Os relatos transcritos abaixo justificam a escolha do Serviço nesta perspectiva:

é porque a primeira vez que eu fui atendido aqui fui, fui bem, né, saí daqui curado, então eu voltei, voltei a ficar doente de novo e daí retornei aqui (João, 44 anos).

[...] eu como sendo portador do HIV, eu tive informações de pessoas que aqui tratavam nesse assunto, daí eu procurei para isso, para melhor, né, atendimento meu, né, dessa doença (Paulo, 30 anos).

Também contribui para o aumento da procura por atendimento nas emergências, o encaminhamento indiscriminado por profissionais médicos para estes serviços. De acordo com Stein:

[...] caracterizar uma consulta como de urgência pode ser 'aprendido', em parte, a partir do modelo de atendimento do médico. Se um paciente é orientado por um médico a ir à emergência, é muito razoável para o paciente pressupor que um atendimento imediato é necessário(12:42).

Esta forma de acesso ao Serviço de Emergência pode ser evidenciada por relatos do tipo:

[...] na onco, a gente sempre tem o aviso de que qualquer coisa se passe na emergência, né, qualquer paciente da oncologia recebe essa indicação (José, 37 anos).

Os relatos revelam, também, que a expressão qualquer coisa mencionada no depoimento pode ser interpretada como uma permissão médica para uma avaliação leiga da situação de saúde sendo um dos determinantes de procura pelo serviço.

\subsection{Aquela seleção}

Mais do que uma percepção e uma conseqüente motivação para tratar necessidades de saúde, é preciso que haja serviços de saúde disponíveis para este fim. Neste sentido, o conceito de acesso tem sido, cada vez mais, traduzido como assistência médica imediata ${ }^{(13)}$

Como conseqüência, a população tem buscado encontrar acessibilidade no sentido semântico da palavra, ou seja, a facilidade na obtenção(14) do atendimento de saúde, o que tem sido encontrado nos serviços de emergência.

Esta disponibilidade faz com que a demanda por atendimento esteja constantemente acima da capacidade de acolhimento por parte do serviço. Se por um lado o usuário alcança um nível de satisfação pelo acesso, por outro sofre as conseqüências de uma inevitável superlotação que se traduz na queda da qualidade da assistência.

No serviço de emergência em análise, a realidade não é diferente, sendo que atualmente há a necessidade de, de alguma forma, reprimir o excesso de demanda que procura por atendimento, mesmo por situações não urgentes. $\mathrm{O}$ acesso ao Serviço vem se desenvolvendo segundo uma lógica repressiva, pois ao usuário são impostos bloqueios desde a sua chegada ao setor, de forma que ele é obrigado a passar por um funil até conseguir ou não o atendimento pretendido.
Neste estudo, foram identificados três momentos de triagem de acordo com os depoimentos dos informantes.

A primeira triagem é realizada por um segurança do hospital por meio de uma avaliação subsidiada por um conhecimento leigo. Um estudo a este respeito identificou a mesma dinâmica de funcionamento denominado-a de classificação de demandas. ${ }^{(15)}$

No presente estudo foi identificada ainda uma segunda triagem, a qual é realizada no guichê de marcação de consultas, por funcionárias administrativas. Aqui também são utilizados conhecimentos leigos e critérios internos ao Serviço como forma de subsidiar uma avaliação de saúde. Isto é realizado através de um vidro, por meio de perguntas sobre o motivo da procura.

O relato a seguir explicita, de modo sucinto, como esta dinâmica de funcionamento pode se refletir no acesso dos usuários:

bem, eu cheguei na emergência, na recepção. Na primeira vez que eu cheguei de imediato não fui atendido. Falaram que estava cheio a emergência e..eu como tava muito mal acabei me sentando. Tava acompanhado e sentei em frente à recepção ali, e a moça viu que eu tava passando mal e depois de meia hora me chamou e acabei sendo atendido, passei pela aquela seleção que eu não sei exatamente como chama [...] (José, 37 anos).

A terceira etapa de avaliação, denominada neste estudo de terceira triagem, é realizada pela equipe de enfermagem, sendo que é conferida à enfermeira, a atribuição de decidir sobre o destino do usuário a partir dali. Esta triagem caracterizase pela utilização do conhecimento científico como instrumento de avaliação. Aqui são empregados critérios que resultam em uma classificação da situação de saúde do usuário, segundo a qual serão subsidiadas as decisões.

O relato a seguir explicita a visão do usuário em relação à triagem técnica:

a gente chega, a gente aguarda; um enfermeiro vem e vê a temperatura da gente, vê os sinais como é que estão, vê se realmente é caso de emergência. Caso não for caso de emergência, ele manda na recepção pra fazê um boletim e marca uma hora pra ti, uma hora mais conveniente (Joaquim, 40 anos).

A decisão quanto ao atendimento por ocasião desta triagem, poderá ser influenciada também pela insistência do usuário, fato que pode ser gerador de conflitos neste momento, como mostra o relato:

[...] a última vez que eu cheguei, eu não fui muito bem atendido, né, pelo enfermeiro que tava no local. Ele ... não sei, implicou com a minha cara, não sei o que é, queria que eu viesse embora, disse que não era preciso, que não sei o quê. Aí chamou a minha mãe, e a minha mãe disse que a médica tinha dito que tanto podia ser grave como podia não ser, né. Aí ele resolveu me avaliar e passar pro médico (Ricardo, 28 anos).

\subsection{Aqui se faz tudo}

As ações e práticas realizadas pelos serviços de saúde tendem a ser resolutivas na medida em que são capazes de resolver os problemas dos usuários ${ }^{(16)}$.

Nesta ótica, uma ação resolutiva pode se referir a um atendimento imediato, com a conseqüente prescrição de um medicamento, ou a realização de um curativo ou de outra terapêutica qualquer. Porém, o que gera a satisfação do usuário é o significado de imediatismo que caracteriza a ação.

O usuário vê na relação trabalhador de saúde/usuário um aspecto decisivo na solução de seus problemas, pois se a relação for de acolhimento por parte do primeiro, a expectativa é 
de que as ações sejam mais efetivas e satisfatórias ${ }^{(17)}$.

Também é nos setores de emergência que a população parece encontrar resolutividade, ou seja, o oposto do que encontra em outros serviços de menor complexidade da rede pública. A impossibilidade ou demora em conseguir uma consulta, o agendamento de exames diagnósticos para datas longínquas, com a conseqüente demora no retorno para uma reconsulta, gera na população usuária uma inconformidade, fazendo com que resulte na procura por serviços mais resolutivos. Este fato foi evidenciado em estudo onde os usuários relataram como motivos de procura à emergência, conseguir fazer o exame e porque a consulta que tem marcada é para o mês que vem ${ }^{(12)}$. Desta maneira, a resolutividade se configurou no motivo de escolha do serviço, pois neste, o usuário encontrou a possibilidade de resolver sua necessidade de saúde de forma imediata.

Na percepção dos usuários do Serviço de Emergência em estudo, a resolutividade se traduz pelo imediatismo tanto das ações diagnósticas, quanto terapêuticas. $O$ atendimento acontece de uma forma resolutiva, uma vez que se a pessoa tem febre, dão remédio ali mesmo, já fazem todos os exames, e ali tu aguarda os resultados, tu chega e já faz a medicação na hora, me receitaram remédio e comecei o tratamento já, já tomei injeção, já fui pro soro.

Ao mesmo tempo em que o usuário caracteriza a ação como imediata, mostra um entendimento de que a ação diagnóstica é condição para que seja indicada uma ação terapêutica, como mostra o relato a seguir:

[...] fiz ecografia, né, fiz a ecografia, fiz exame de sangue na hora, foi tudo feito na hora e aonde constou que eu tinha pedra na vesícula, que tinha que ficar pra operar (Marisa, 38 anos).

O hospital é considerado como um local que congrega a maior parte dos recursos da medicina oficial, que além da consulta médica, dá remédios, faz injeção, realiza exames, enquanto a procura ao "postinho", resulta somente na consulta médica(11). A mesma percepção dos informantes de um estudo foi identificada no que diz respeito à utilização do hospital em detrimento dos serviços ambulatoriais da rede básica ${ }^{(18)}$.

O acesso ao Serviço de Emergência representa também um viés para conseguir uma internação em outros setores do hospital, uma vez que o caminho natural para este fim seria a já comentada "peregrinação" pelos serviços de saúde e uma conseqüente espera pela desocupação de um leito. Nesta perspectiva, na visão de Fátima, 47 anos, a Emergência é válida:

[...] porque é um modo que tu tem de chegar até aqui ... ... no caso de tu precisar de um leito, uma coisa, tu tem. Se tu não precisar, tudo bem, tu vai embora dali, né, mas se tu precisar ... tu vem [para unidade de internação] (Fátima, 47 anos).

Esta estratégia não é de uso exclusivo do usuário, uma vez que o encaminhamento por médicos do ambulatório do hospital configura-se em um freqüente motivo de procura ao Serviço de Emergência. A falta de leitos no hospital, faz com que o Serviço seja visualizado como uma trilha secundária para a efetivação de uma internação, ou até mesmo para a própria internação.

\subsection{Não é nada agradável}

A permanência em setores de emergência, atualmente, representa a possibilidade de vivenciar ambientes superlotados e, portanto, passíveis de despertar nos indivíduos os mais diversos tipos de sentimentos.

Neste sentido, o estudo identificou sentimentos de medo relacionados à própria condição de portar uma doença, como mostra o depoimento:

eu me senti [...] , eu estava apavorado, achando que ia morrer, mas eu tive bastante assistência médica, bastante carinho por parte da, da equipe de enfermagem e equipe médica em geral, né. Foram bastante atenciosos comigo, daí essa segurança, né, mas é uma situação triste que você não imagina passar por aquilo, mas acontece, enfim, você tem que tentar superar, né. Eu tentava ser paciente, rezava por conseguir um leito pra vê se melhorava a situação (José, 37 anos).

Esta declaração demonstra, além do que já foi comentado, aspectos que contribuem para determinar o sentimento do usuário durante sua permanência na Emergência. Se por um lado, a atenção dispensada pela equipe de saúde contribui para proporcionar segurança, por outro as condições ambientais e de acomodação colaboram para aumentar o sofrimento, pois José ...rezava para conseguir um leito pra vê se melhorava a situação. Ainda no último depoimento, fica explícito um sentimento bastante comum nas pessoas, de que as coisas ruins da vida só acontecem com os outros.

Quanto à relação equipe de saúde/usuário, muito tem se falado que o atendimento prestado acontece somente em uma dimensão biológica, sem que aspectos individuais sejam contemplados nesta relação ${ }^{(19)}$. Porém, este estudo revela que o usuário percebe esta relação de uma maneira diferente, pois refere ...bastante carinho por parte da equipe de enfermagem e equipe médica..., .... partir que tu chamasse elas, elas tavam junto contigo, sempre ajudando....

Outro aspecto identificado, diz respeito à dificuldade de acomodação adequada gerada pela superlotação do Serviço, sendo que isto resulta em sentimentos relacionados ao desconforto de permanecer sentado, explicitado na fala a seguir: ah, eu não tava acostumado, eu me senti mal acomodado. As primeiras horas eu até suportei, mas depois a gente se sente meio inconfortado. Durante a noite a gente [...], problemas, dores, cansado, sente sono, não tem onde deitar, aí tem que dar um jeito, tá entrando pros consultórios, que tem as macas ali nos consultórios, né, pra poder tirar ali uma hora, duas de sono, e daí o cara descansa e tem que levantar, sentar na cadeira de novo, né. Acho que é uma espera, né, sacrificada, exige um pouco de sacrifício, e a pessoa doente acaba se decaindo mais, devido a isso, né (Paulo 30 anos).

Por outro lado, a convivência dos usuários no mesmo ambiente, gera um sentimento de uns em relação aos outros, construído a partir de quem, além de experienciar o contexto de atendimento, também se torna espectador dos eventos que acontecem ao seu redor:

ah, infelizmente não é nada agradável, é até...bastante assustador. Eu em casa, eu tinha medo de voltar pra emergência pra...não me encontrar novamente nessa situação; até nem tanto por mim, que eu fui super bem atendido e tive a felicidade de não ficar tanto tempo nesse local, mas mais pelo que acontece ao redor; outros pacientes que tão ali com uma idade bem avançada e tão ali sentados ali há três dias e tomando medicação, exaustos e...é bastante assustador (José, 37 anos).

Os depoimentos mostram uma tendência do usuário em visualizar no outro uma condição pior que a sua, o que pode ser interpretado como uma forma de mecanismo de defesa, enquanto ele se percebe, de uma certa forma, privilegiado.

Da mesma forma, há no usuário uma necessidade de manter sua privacidade enquanto indivíduo, mesmo em um ambiente superlotado onde as pessoas são obrigadas a permanecer muito próximas umas das outras. Este fato revela um sentimento de auto-proteção, uma vez que esta proximidade 
pode representar um risco para sua situação atual de saúde:

[...] a gente se sente ruim, né, se sente mal, vendo aquelas pessoas ali; assim ó, não discriminando ninguém, mas tem pessoa assim, que por exemplo... às vezes tem aquelas pessoas cheia de piolho, cheias de sarna, né ... eu, por exemplo, se eu vejo uma pessoa assim, eu nem procuro chegar muito por perto, né porque já tenho problema suficiente, ainda vou pegar mais aquele monte de problema deles, né? (Sandra, 47 anos).

\subsection{Só tenho a agradecer}

A qualidade dos serviços, de qualquer natureza, oferecidos à população, é um assunto que vem sendo amplamente discutido, desde que o consumidor foi reconhecido como o componente mais importante no processo que se estabelece na venda de um produto.

Da mesma forma, os serviços de saúde cada vez mais vêm dando importância a este processo e reconhecendo no usuário a finalidade principal de oferecer cuidados de qualidade e efetivos.

A satisfação do usuário pode, então, representar um eficiente instrumento de avaliação dos serviços, na medida em que representa um julgamento sobre a qualidade do cuidado prestado $^{(20)}$.

É na perspectiva da relação que se estabelece entre usuário/serviço de saúde, que esta análise possibilita a discussão de alguns aspectos que compõem a avaliação de um Serviço de Emergência ${ }^{(21)}$. Embora não tenha sido solicitado formalmente aos informantes da pesquisa que avaliassem o Serviço em estudo, os depoimentos constantemente foram permeados por expressões relacionadas a esse aspecto.

A totalidade dos informantes sente-se agradecida pelo atendimento recebido no Serviço de Emergência, objeto desta análise, sendo comum os depoimentos iniciarem por expressões do tipo ...já vou te falar antes, não tenho nada para reclamar.... Por outro lado, este tipo de declaração pressupõe um receio de tecer críticas em relação a um Serviço que, apesar de todas as dificuldades, acolhe o usuário. Tal sentimento se torna evidente quando:

os pacientes se vêem, muitas vezes, induzidos a faze críticas ao atendimento dispensado pelo HMMC [Hospita Municipal Miguel Couto], mas assumem um discurso contraditório entre o revelar das deficiências do serviço e a gratidão por terem sido atendidos ali(15:116)

Assim, podem ser identificados diversos critérios que subsidiam a opinião dos usuários em relação ao atendimento ofertado na Emergência, sendo que estes podem dizer respeito ao Serviço, do ponto de vista de estrutura e funcionamento, como às atitudes dos profissionais.

Em geral, os depoimentos dos usuários do Serviço de Emergência são permeados por críticas, mas ao mesmo tempo demonstram um reconhecimento em relação ao esforço que os profissionais fazem para atender todos, revelando um discurso contraditório, como mostra o depoimento de Neusa:

[...] é muita gente pra pouco espaço e pessoal pra atender. Acho que se tivesse mais espaço, mais pessoal, aí não tinha aquele tumulto ali de tanta gente doente, porque chega um com uma coisa, outro com outra ... , já vem mal, né, e daí tudo ali tem que atender os mesmos que estão ali de plantão, né. Daí, as vezes, eles mesmo não conseguem atender todo mundo como eles querem, né. Mas fui bem atendida lá embaixo, apesar da demora, coisa assim, eu achei que fui bem atendida, né,...porque eles não abandonam a gente né. Enquanto tão lá, tão servindo comida pra quem precisa comer, né, chazinho, soro, eles fazem de tudo lá embaixo, naquela sala, até poder encaminhar pra um leito aqui em cima (Neusa, 38 anos).

Também é comum o reconhecimento pelo esforço dos profissionais em tentar diminuir o desconforto gerado pela necessidade de permanecer sentado à noite. Os usuários fazem referência ao uso de consultórios como possibilidade de deitar para ... tirar um cochilo ...

eu deitei uma vez, foi a última vez agora, eu deitei duas horas. Só porque eu tava muito ruim, eles sentiram que eu tava ruim, me deitaram lá, numa cama lá, no consultório do médico lá, numa maca lá (João, 44 anos).

Finalmente, pode-se constatar que a satisfação do usuário do Serviço de Emergência está intimamente vinculada à disponibilidade do mesmo em resolver as necessidades de saúde daqueles que o procuram. Isto é evidenciado pela capacidade do usuário em separar as experiências boas das ruins, prevalecendo em sua avaliação o sentimento de ter sido bem atendido, como mostram os depoimentos:

[...] não tenho queixa nenhuma, sou muito bem atendido lá, tirando esta parte, fui muito bem atendido lá (Ricardo, 28 anos).

[...] eu gostaria de agradecer o serviço médico que tão me prestando, que eu acho que pra mim tá sendo bom, né, a atenção, apesar das alteração, dos negócio meio forçado e...ao pessoal da equipe médica, os enfermeiro em geral, né, o meu agradecimento (Paulo, 30 anos).

\section{Considerações finais}

Atualmente, a superlotação se configura no maior desafio enfrentado pelo Serviço de Emergência, uma vez que este evento gera dificuldades de prestar um atendimento de qualidade.

O presente estudo permitiu conhecer, por meio de depoimentos dos informantes e com base em observações, como os usuários percebem o processo que envolve seu atendimento, contemplando aspectos relacionados à procura pelo Serviço de Emergência, bem como a trajetória que estes percorrem desde a chegada até a resolução de seus problemas de saúde. Embora o estudo de caso, por sua própria característica, não pretenda generalizações, ressaltamos que alguns achados deste estudo, específicos do contexto estudado, possam ocorrer de modo semelhante em outros serviços de emergência e desta forma contribuir para outros estudos.

A procura ao Serviço de Emergência pode acontecer por motivos diversos. Com base nos dados obtidos, identificouse que essa procura se dá a partir de referências, as quais podem ser pessoais, de pessoas conhecidas ou por encaminhamento médico. Assim, experiências anteriores positivas fazem com que o usuário procure por atendimento no mesmo local. Também é expressivo o número de usuários que procuram a Emergência por serem vinculados ao ambulatório de especialidades, onde seus médicos orientam que a procurem no caso de necessidade. É importante salientar que este tipo de orientação pode levar o usuário a avaliar suas necessidades como merecedoras de atendimento de emergência, resultando, muitas vezes, em uma má utilização do Serviço.

Como conseqüência da busca à Emergência, é imposta ao usuário a condição dele passar por uma triagem, a qual ele denomina de "seleção", devido à necessidade de reprimir a demanda por atendimento, que atualmente é bastante grande. Foram identificados três momentos de triagem, sendo que os dois primeiros são realizados por um segurança e por servidores administrativos, portanto, com base no conhecimento 
leigo. Somente a terceira triagem é efetivada pela equipe de saúde, o que aumenta a possibilidade de ocorrerem erros na avaliação de saúde do usuário.

Contribui para a motivação do usuário em ser atendido na Emergência, o fato deste achar que as ações de saúde que Ihe são oferecidas são resolutivas para os seus problemas. As ações são percebidas como imediatas, apesar de condicionadas a uma espera em condições inadequadas, as quais são geradoras de desconforto físico.

Além disso, a Emergência é percebida tanto pelos usuários quanto pelos médicos como um viés para conseguir uma internação hospitalar. Estes fatos demonstram a descaracterização da Emergência de sua concepção original de atendimentos rápidos e com alta rotatividade. Ao contrário disso, os usuários estão sendo internados no próprio setor, por conta da escassez de leitos no restante do hospital.

A necessidade de permanecer por um tempo prolongado na unidade de emergência, no contexto observado, faz aflorar no usuário sentimentos relacionados à maneira como ele se percebe naquele ambiente, bem como sentimentos gerados a partir da condição de espectador do que acontece com os outros usuários.

Os sentimentos auto-percebidos revelaram medo desconforto, cansaço, depressão. Mas por outro lado, o carinho ofertado pela equipe de saúde, bem como a sua disponibilidade em ajudar, são considerados como geradores de segurança. Também fica explícito o sentimento de auto-proteção quando os outros casos são sempre considerados piores que o seu, assim como o de manutenção da privacidade quando a proximidade com o outro pode ser considerada como um risco à sua integridade física.

Há uma dificuldade em tecer críticas ao Serviço, resultando em um discurso contraditório, pois os aspectos negativos percebidos são comumente abrandados pelo sentimento de agradecimento pela disponibilidade do Serviço em prestar atendimento, mesmo em condições inadequadas. Entretanto, não se pode afirmar que o mesmo ocorreria com indivíduos entrevistados fora da instituição, pois o grupo participante deste estudo ainda possuía vínculo com a mesma, o que pode ter influenciado sua opinião quanto ao atendimento recebido na emergência.

\section{Referências}

1. Gomes AM. Emergência: planejamento e organização da unidade assistência de enfermagem. São Paulo: EPU; 1994.

2. Senado Federal (BR). Constituição: República Federativa do Brasil: 1988. Brasília (DF): Centro Gráfico; 1988.

3. Mendes EV. As políticas de saúde no Brasil dos anos 80: a conformação da reforma sanitária e a construção da hegemonia do projeto neoliberal. In: Mendes EV, organizador. Distrito sanitário: o processo social de mudança das práticas sanitárias do sistema único de saúde. $3^{a}$ ed. São Paulo: HUCITEC-ABRASCO; 1995. 310 p. p. 19-91. (Saúde em debate; vol 55)

4. Lüdke $M$, Andrë $M$. Pesquisa qualitativa em educação: abordagens qualitativas. São Paulo: EPU; 1986. 99p. p. 11-24.

5. Triviños ANS. Introdução à pesquisa em ciências sociais: a pesquisa qualitativa em educação: o positivismo, a fenomenologia, o marxismo. São Paulo: Atlas; 1987. p. 116-75.

6. Minayo MCS. O desafio do conhecimento: pesquisa qualitativa em saúde. $2^{\mathrm{a}}$ ed. São Paulo: HUCITEC-ABRASCO; 1993.
7. Ferreira JF. O corpo sígnico. In: Alves PC, Minayo MCS, organizadores. Saúde e doença: um olhar antropológico. Rio de Janeiro: FIOCRUZ; 1994. p. 101-12.

8. Helman CG. Cultura, saúde e doença. $2^{\mathrm{a}}$ ed. Porto Alegre (RS): Artes Médicas; 1994. p. 70-99

9. Paim JS. A reforma sanitária e os modelos assistenciais. In: Rouquayrol MZ. Epidemiologia e saúde. $4^{a}$ ed. Rio de Janeiro: MEDSI; 1994. p. $455-66$.

10. Piva J, Ribeiro CA, Portella V, Pinto TAT, Rosa NG. Relatório 1996. Porto Alegre (RS): Serviço de Emergência, HCPA; 1996. 24 p.

11. Knauth DR. Os caminhos da cura: sistema de representações e práticas sociais sobre doença e cura em uma vila de classes populares [dissertação de Mestrado em Antropologia Social]. Porto Alegre (RS): Instituto de Filosofia e Ciências Humanas, Universidade Federal do Rio Grande do Sul; 1991. 187 f.

12. Stein AT. Acesso a atendimento médico continuado: uma estratégia para reduzir a utilização de consultas não urgentes em serviços de emergência [tese de Doutorado em Clínica Médica]. Porto Alegre (RS): Faculdade de Medicina, Universidade Federal do Rio Grande do Sul; 1998. $214 \mathrm{f}$.

13. Cohn A, Nunes E, Jaboci PR, Karsch US. A saúde como direito e como serviço. São Paulo: Cortez; 1991. p. 67-91.

14. Ferreira ABH. Dicionário Aurélio da língua portuguesa. Rio de Janeiro: Nova Fronteira; 1988. Acessibilidade; p. 22

15. Skaba MMVF. O vício da adrenalina: etnografia da violência num hospital de emergência [dissertação de Mestrado em Saúde Pública]. Rio de Janeiro: Departamento de Ciências Sociais, Escola Nacional de Saúde Pública, Fundação Osvaldo Cruz; 1997. 143 f.

16. Carvalho GI, Santos L. Sistema único de saúde: comentários à Lei Orgânica da Saúde (Lei 8.080/90 e Lei 8.142/90). $2^{\mathrm{a}}$ ed. São Paulo: HUCITEC; 1995.

17. Merhy EE. Em busca da qualidade dos serviços de saúde: os serviços de porta aberta para a saúde e o modelo tecno-assistencial em defesa da vida (ou como aproveitar os ruídos do cotidiano dos serviços de saúde e colegiadamente reorganizar o processo de trabalho na busca da qualidade das ações de saúde). In: Cecílio LCO, organizador. Inventando a mudança na saúde. São Paulo: HUCITEC; 1994. p. 117-60. (Saúde em debate; vol 73).

18. Canesqui AM. População e serviços de saúde: consumo e avaliação dos serviços de saúde. In: Spínola AWP, Sá ENC, Westphal MF. Pesquisa social em saúde. São Paulo: Cortez; 1992. p. 175-205.

19. Gomes LC, Fraga MNO. Doenças, hospitalização e ansiedade: uma abordagem em saúde mental. Revista Brasileira de Enfermagem, Brasília (DF) 1997 jul/set;50(3):425-40.

20. Santos MP. Avaliação da qualidade dos serviços públicos de atenção a saúde da criança sob a ótica do usuário. Revista Brasileira de Enfermagem, Brasília (DF), 1995 abr/jun;48(2):109-19.

21. Oliveira FA. Serviços de saúde e seus usuários: comunicação entre culturas em uma unidade de saúde comunitária [dissertação de Mestrado em Antropologia Social]. Porto Alegre (RS): Instituto de Filosofia e Ciências Humanas, Universidade Federal do Rio Grande do Sul; 1998. $206 \mathrm{f}$.

Data de recebimento: $12 / 02 / 2003$

Data de aprovação: 26/06/2003 